\title{
Reintervention technique with insertion of an uncovered metal stent by a 5.4-Fr delivery system for an occluded endoscopic ultrasound-guided hepaticogastrostomy stent
}

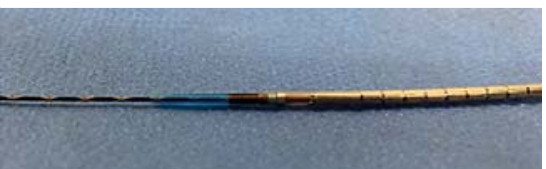

- Fig. 1 The novel uncovered self-expandable metal stent with a 5.4-Fr stent delivery system (laser cut type, YABUSAME; KANEKA Medical, Osaka, Japan).

Endoscopic ultrasound-guided hepaticogastrostomy (EUS-HGS) is indicated for patients with failed endoscopic retrograde cholangiopancreatography (ERCP) [1]. The clinical benefit of EUS-HGS using a long-length, partially covered, self-expandable metal stent (PCSEMS) to prevent stent migration has been reported $[2,3]$. However, reintervention can be challenging in the event of stent obstruction because biliary access through a long-length PCSEMS is often difficult. Biliary access through the mesh of the EUS-HGS stent may be a useful reintervention technique $[4,5]$. In this procedure, insertion of the device into the biliary tract is a limiting step because the lumen of the mesh is relatively narrow. $A$ novel uncovered self-expandable metal stent (UCSEMS) has recently become available in Japan (YABUSAME; KANEKA Medical, Osaka, Japan) (\Fig. 1). As the diameter of the stent delivery system is only 5.4 Fr and the tip is extremely tapered, stent delivery is performed by insertion along a guidewire. Here we describe the technique of reintervention through the mesh of an occluded EUS-HGS stent using the novel UCSEMS ( $\triangleright$ Video 1 ).

A 78-year-old man had undergone EUSHGS with a long-length PCSEMS for duodenal obstruction caused by pancreatic head cancer 6 months previously. Although chemotherapy was performed,

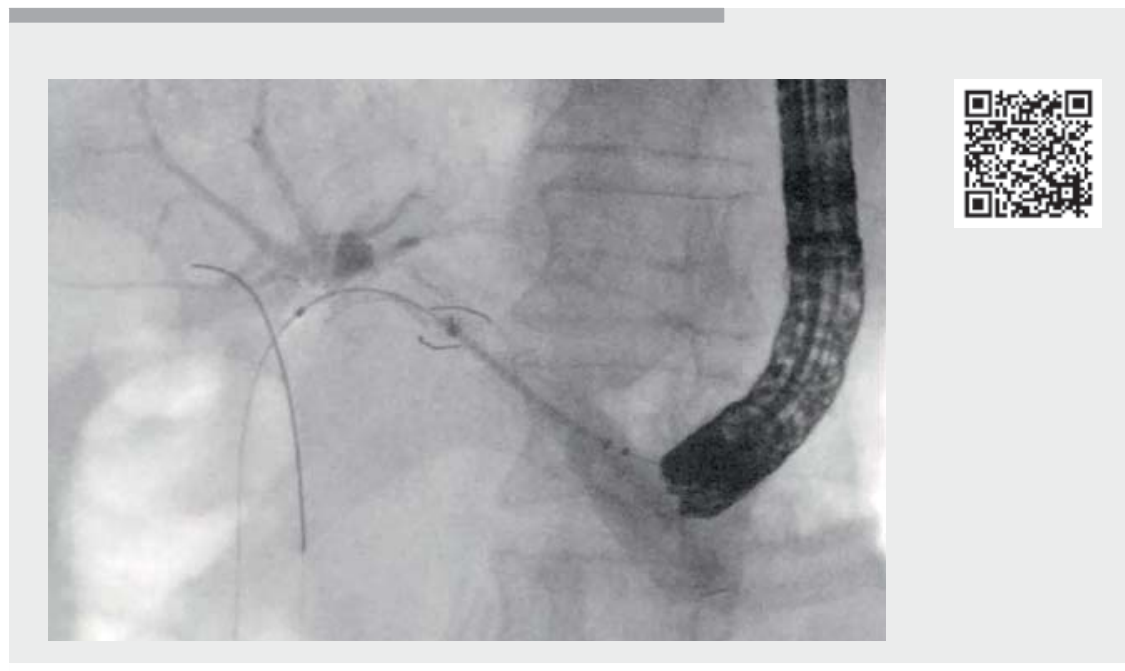

$\checkmark$ Video 1 The novel uncovered self-expandable metal stent delivery system was inserted into the biliary tract through the mesh of an endoscopic ultrasound-guided hepaticogastrostomy stent.

obstructive jaundice occurred due to stent obstruction, and reintervention was attempted. After inserting an ERCP catheter into the biliary tract through the mesh of the PCSEMS ( $\mathbf{F i g . 2 a ) , ~ a ~}$ 0.025-inch guidewire was deployed. Cholangiography revealed stent occlusion ( Fig.2b). The stent delivery system was then successfully inserted through the PCSEMS ( $\triangleright$ Fig. $\mathbf{2 c}$ ), and the stent was successfully deployed across the stricture site using the novel UCSEMS $(8 \times 6 \mathrm{~cm}$ ) with no adverse events ( $>$ Fig. 2 d).

In the case of occluded EUS-HGS stent, the technique of reintervention through its mesh using the novel UCSEMS appears to be useful and should be further evaluated in a greater number of patients.

Endoscopy_UCTN_Code_CPL_1AL_2AD

\section{Competing interests}

The authors declare that they have no conflict of interest.

The authors

Takeshi Ogura, Atsushi Okuda Nishioka, Masanori Yamada, Kazuhide Higuchi

2nd Department of Internal Medicine, Osaka Medical College, Osaka, Japan

\section{Corresponding author}

\section{Takeshi Ogura, MD}

2nd Department of Internal Medicine, Osaka Medical College, 2-7 Daigakuchou, Takatsukishi, Osaka 569-8686, Japan oguratakeshi0411@yahoo.co.jp 

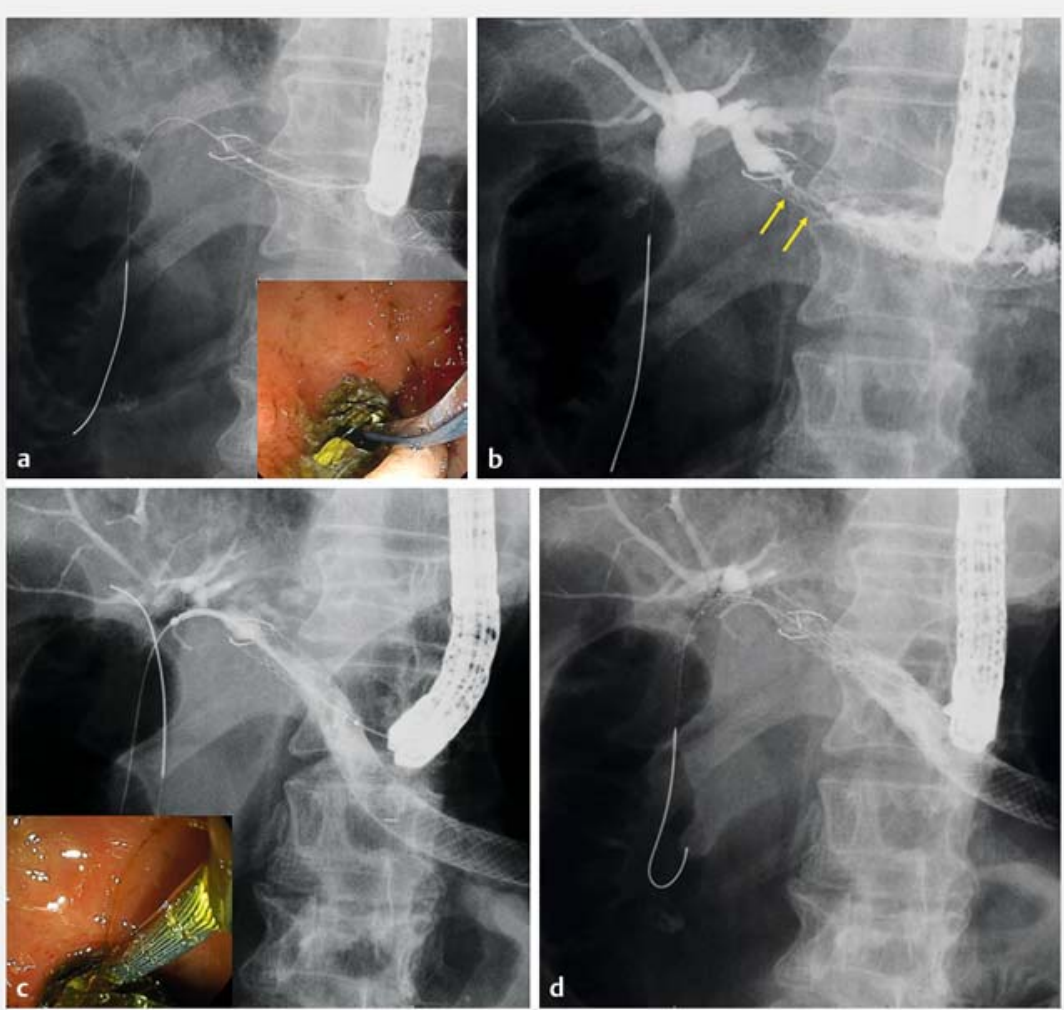

- Fig. 2 Reintervention through the occluded stent. a An endoscopic retrograde cholangiopancreatography catheter was inserted into the biliary tract through the mesh of the endoscopic ultrasound-guided hepaticogastrostomy stent. b Obstruction of the stent was apparent (arrow). c The novel uncovered self-expandable metal stent delivery system was inserted across the stricture site into the biliary tract. $\mathbf{d}$ Stent deployment was successfully performed.
Bibliography

Endoscopy 2021; 53: E462-E463

DOI $10.1055 / \mathrm{a}-1346-8044$

ISSN 0013-726X

published online 4.2.2021

(C) 2021. Thieme. All rights reserved.

Georg Thieme Verlag KG, Rüdigerstraße 14, 70469 Stuttgart, Germany

\section{ENDOSCOPY E-VIDEOS}

https://eref.thieme.de/e-videos

回回 Endoscopy E-Videos is a free access online section, reporting 回制 on interesting cases and new techniques in gastroenterological endoscopy. All papers include a high quality video and all contributions are freely accessible online.

This section has its own submission website at https://mc.manuscriptcentral.com/e-videos

\section{References}

[1] Dhindsa BS, Mashiana HS, Dhaliwal A et al. EUS-guided biliary drainage: a systematic review and meta-analysis. Endosc Ultrasound 2020; 9: 101-109

[2] Nakai Y, Sato T, Hakuta R et al. Long-term outcomes of a long, partially covered metal stent for EUS-guided hepaticogastrostomy in patients with malignant biliary obstruction (with video). Gastrointest Endosc 2020 92: 623-631.e1

[3] Ogura T, Yamamoto K, Sano T et al. Stent length is impact factor associated with stent patency in endoscopic ultrasound-guided hepaticogastrostomy. J Gastroenterol Hepatol 2015; 30: 1748-1752

[4] Ogura T, Masuda D, Takeuchi T et al. Simplified reintervention method of EUS-guided hepaticogastrostomy stent obstruction. Gastrointest Endosc 2016; 83: 831

[5] Maehara K, Hijioka S, Wu SYS et al. Re-intervention for recurrent biliary obstruction after endoscopic ultrasound hepaticogastrostomy with partially covered self-expandable metal stent. Endoscopy 2019; 51: E297-E298 